\title{
De volta para o futuro... \\ retrocessos na atual política de formação docente
}

\author{
De vuelta para el futuro...
}

retrocesos en la política actual de formación docente

\section{Back to the future...}

setbacks in the current teacher education policy

VERA BAZZO

Universidade Federal de Santa Catarina, Florianópolis-SC, Brasil.

LEDA SCHEIBE ${ }^{* *}$

Universidade Federal de Santa Catarina, Florianópolis-SC, Brasil.

\begin{abstract}
RESUMO: Este artigo tem como objetivo realizar uma leitura crítico-comparativa das Diretrizes Curriculares Nacionais para a formação inicial em nível superior (cursos de licenciatura, cursos de formação pedagógica para graduados e cursos de segunda licenciatura) e para a formação continuada, definidas pela Resolução $\mathrm{CNE} / \mathrm{CP} \mathrm{n}^{0}$ 02/2015 e a nova versão de Diretrizes, aprovadas pela Resolução $\mathrm{CNE} / \mathrm{CP}$ n ${ }^{\circ}$ 2, de 20 de dezembro de 2019 e homologada pela Portaria no 2.167, de 19/12/2019, assinada pelo Ministro de Estado da Educação - substituto -, Antônio Paulo Vogel de Medeiros.

Palavras-chave: Políticas educacionais. Formação docente. Diretrizes Curriculares Nacionais.
\end{abstract}

RESUMEN: Este artículo tiene como objetivo realizar una lectura crítica comparativa de las Directrices Curriculares Nacionales para la formación inicial en Educación Superior (grados, cursos de capacitación

* É Doutora em Educação pela Universidade Federal do Rio Grande do Sul. Professora Titula aposentada da Universidade Federal de Santa Catarina. Atua como membro do Comitê editorial da Revista Retratos da Escola. E-mail: <vbazzo@gmail.com>.

** É Doutora em Educação pela Pontifícia Universidade Católica de São Paulo. Professora Titular Emérita, aposentada da Universidade Federal de Santa Catarina. Atualmente é Editora da Revista Retratos da Escola (Esforce/CNTE). Florianópolis, SC- Brasil. E-mail: <lscheibe@uol.com.br>. 
pedagógica para graduados y cursos de segundo grado) y Educación Continua, definida por la Resolución CNE/CP 02/2015 y las nuevas Directrices, aprobadas por la Resolución CNE/CPnํㅡㄹ de 20 de diciembre de 2019 y homologada por la Ordenanza no 2,167, del 19/12/2019, firmada por el Ministro de Educación - sustituto -, Antônio Paulo Vogel de Medeiros

Palabras clave: Palabras clave: Políticas educativas. Formación del profesorado. Directrices Curriculares Nacionales 2019.

\begin{abstract}
This article aims to make a critical-comparative reading of the National Curriculum Guidelines for initial higher education (undergraduate courses, pedagogical training courses for graduates and second degree courses) and for continuing education, defined by Resolution CNE/CP no 02/2015 and the new version of the Guidelines, approved by Resolution CNE/CP nํ2, of December 20th, 2019 and ratified by Ordinance $n^{0}$ 2,167, of 12/19/2019, signed by the Minister of State of Education - substitute-, Antônio Paulo Vogel de Medeiros.

Keywords: Educational policies. Teacher training. National Curriculum Guidelines.
\end{abstract}

\title{
Introdução
}

גרי

de todos conhecida a importância e a necessidade da estruturação de um Sistema Nacional de Educação no país que contemple também um subsistema nacional de formação e de valorização dos profissionais do magistério. Não por acaso, isso sempre foi tema das conferências brasileiras de educação, (CBE), ao longo de suas edições, e, mais recentemente, das conferências nacionais de educação (Conae 2010 e 2014), ambas sob os auspícios do Estado, assim como da Conape 2018, realizada por esforço das entidades que assumiram a coordenação do Fórum Nacional Popular de Educação, depois do Golpe de Estado que afastou Dilma Rousseff da Presidência da República.

Por muitos anos, desde a aprovação da Lei no 9.394, de 20 de dezembro de 1996 (BRASIL, 1996), a Lei de Diretrizes e Bases da Educação Brasileira (LDB), em seus artigos 61 até 67, incluindo o Artigo 87, que dispõem sobre a formação de profissionais do magistério, o Conselho Nacional de Educação (CNE/MEC) vem tratando de criar legislações que orientem as instituições formadoras sobre como deve ser feita essa formação. As resoluções conhecidas e sobre cuja elaboração os educadores nos debruçamos exaustivamente nos anos iniciais deste século, ainda sob o governo neoliberal de Fernando Henrique Cardoso (1994-2002), 
foram as Resoluções CNE/CP nº 1, de 18 de fevereiro de 2002 (BRASIL, 2002a) , e a CNE/CP $\mathrm{n}^{\mathrm{o}}$ 2, de 19 de fevereiro (BRASIL, 2002b), que tiveram efetiva vigência durante os anos dos governos Lula e Dilma, de 2003 a 2015, quando foram substituídas pela Resolução CNE/ CP nº 2, de 1ํ de julho de 2015 (BRASIL, 2015), já no segundo mandato de Dilma Rousseff.

Ainda em pleno processo de implantação da referida Resolução CNE/CP nº 02/2015, que tratava das Diretrizes Curriculares Nacionais para a Formação Inicial e Continuada em Nível Superior de Professores para a Educação Básica, as instituições de ensino superior responsáveis por essa formação começaram a ser impactadas pelas mudanças que se anunciavam em todos os setores da vida nacional e, de forma especial, na Educação, em consequência do Golpe que derrubou o Governo Dilma Rousseff e que instaurou, em 2016, o desastrado Governo Temer.

O conteúdo que embasa a Resolução CNE/CP nº 02/2015 fora discutido amplamente com a comunidade educacional e entendido pelos educadores mais envolvidos com as questões relativas às políticas nacionais de formação de professores como sendo uma importante e bem elaborada síntese das lutas históricas da área em torno ao tema. Assim, recebeu amplo apoio das entidades representativas dos educadores, traduzido em diversas manifestações favoráveis à sua imediata entrada em vigência. Apesar disso, o processo de sua implantação começou a sofrer injustificável demora entre as instituições formadoras.

No processo de troca de orientação política em todas as esferas do poder, no pós-Golpe, a referida legislação, elaborada, discutida e aprovada pelo Conselho Nacional de Educação, cujos membros mais progressistas foram, nesse novo momento, substituídos, teve sua implantação inicialmente atravessada por tentativas oficiais de procrastinação. Foi a pronta reação das entidades representativas dos educadores que impediu tal iniciativa de prosperar imediatamente.

As instituições de ensino superior (IES) que apoiavam a Resolução CNE/CP nº 02/2015, então, trabalharam incansáveis para implantá-la o mais rápido possível. Aquelas que haviam logrado fazer essas mudanças antes de 2016, por sua vez, já estavam realizando seus projetos de formação de acordo com essa resolução. Naquelas em que ainda não houvessem sido implantadas, mas cujos educadores estavam também mobilizados em favor da política de formação abrigada por ela, houve um movimento forte na direção de sua defesa e consequente aplicação. As demais, entre as quais algumas IES públicas, no entanto, ficaram no meio do caminho.

Percebendo o perigo de que a implantação da resolução sofresse algum processo de continuidade, dadas as novas orientações que passaram a hegemonizar as decisões do CNE/MEC, a comunidade educacional, por meio de suas entidades representativas (Anfope, Anped, Anpae, CNTE, entre as mais significativas), reforçou seu apoio à Resolução CNE/CP n⿳o 02/2015 e passou a exigir sua imediata entrada em vigência. Mesmo assim, esse processo foi sofrendo novas postergações por meio do adiamento de datas em sucessivas ações do CNE. 
O prazo estabelecido na Resolução CNE/CP 02/2015 para sua efetiva implantação fora de dois anos após a publicação. Pressupunha-se daí que, até julho de 2017, os cursos de licenciatura deveriam ter reformulado seus projetos pedagógicos. Não foi isso, no entanto, o que aconteceu. Confirmou-se, sim, a tendência ao adiamento, uma vez que, por duas ocasiões, resoluções do próprio Conselho Nacional de Educação tomaram a iniciativa de alterar as datas para a implantação da norma. O primeiro adiamento formal concretizou-se por meio da Resolução CNE/CP nº 1, de 9 de agosto de 2017 (BRASIL, 2017b), que alterou o Art. 22 da Resolução CNE/CP nº 2, de julho de 2015, nos seguintes termos:

Art. $1^{0}$ Alterar o prazo, previsto no Art. 22, da Resolução CNE/CP noำ 2, de $1^{\circ}$ de julho de 2015, que passa a ter a seguinte redação: Art. 22. Os cursos de formação de professores, que se encontram em funcionamento, deverão se adaptar a esta Resolução no prazo de 3 (três) anos, a contar da data de sua publicação.

Art. 2º Esta Resolução entrará em vigor na data de sua publicação (BRASIL, 2017b).

O segundo adiamento formal, bem mais recente, foi respaldado pela Resolução do CNE/CP nº 3, de outubro de 2018 (BRASIL, 2018), o qual, não por acaso, estabeleceu um prazo de quatro anos a partir da data da publicação da Res. CNE/CP nº 02/2015, adiando, portanto, para julho de 2019 a imperiosidade de sua implementação. Próximo desta data, porém, e já urdindo uma nova legislação que tratasse da formação de professores para a educação básica, foi emitida a Resolução CNE/CP nº 1, de 2 de julho deste ano de 2019 (BRASIL, 2019a), cujo Art. $1^{\circ}$ alterou novamente o Art.22 da Res. 02, de 2015, quanto ao prazo de sua já lendária implantação, passando então a vigorar a seguinte redação:

A Res. $\mathrm{CNE} / \mathrm{CP}^{\circ}$ 20 de $1^{\circ}$ de julho de 2015, passa a vigorar com a seguinte alteração: Art.22-Os cursos de formação de professores, que se encontram em funcionamento, deverão se adaptar a esta Resolução no prazo máximo de 2 (dois) anos, contados da publicação da Base Nacional Comum Curricular, BNCC, instituída pela Resolução CNE/ $\mathrm{CP} \mathrm{n}^{\circ}$ 2, de 22 de dezembro de 2017, publicada no Diário Oficial da União (DOU) de 22 de dezembro de 2017 (BRASIL, 2019a).

Curioso mencionar que, apesar de a Resolução CNE/CP nº 02/2015, como um todo, ter sido muito bem recebida pela comunidade acadêmica, que a entendia como resultado do esforço coletivo dos educadores comprometidos com o tema da formação docente nas últimas décadas, sua implantação tenha sido adiada sistematicamente. Inicialmente, as justificativas para os adiamentos referiam-se à complexidade de seu conteúdo e à sua abrangência, além da dificuldade que as modificações trariam para a organização e para o desenvolvimento dos cursos de formação de professores. Depois, em tempos agora claramente regressivos, foi ficando evidente que seus princípios e fundamentos seriam incompatíveis com as orientações advindas do Governo - golpista e conservador - de Temer e de seu sucedâneo, ainda mais reacionário. 
Por óbvio, nesse cenário, o setor educacional passou a sofrer muitas mudanças rapidamente implementadas pelos novos ocupantes do MEC, dada a urgência de o grupo de poder em ascensão obter o controle de tão importante e complexa atividade, como a da formação dos docentes para a educação básica no País. Dessa forma, as instituições formadoras de professores que ainda não haviam concluído o processo de discussão e efetiva implantação da nova normativa viram-se diante do dilema de que caminho tomar nesse desfavorável cenário para tudo o que o texto da Resolução CNE/CP nº 02/2015 defendia e preconizava.

Ficava cada vez mais claro que, para o $\mathrm{CNE} / \mathrm{MEC}$, a questão central dessa resolução e, talvez, o real motivo de todos os adiamentos fora a definição de que a Base Nacional Comum Curricular da Educação Básica-BNCC passasse a ser a chave de leitura para a compreensão das novas políticas educacionais (AGUIAR; DOURADO, 2019). A BNCC, portanto, determinada pela agenda global da manutenção do capitalismo, passou a conduzir e a dominar as discussões e o debate a respeito da formação dos professores para a educação básica. O professor deveria ser formado para atender aos ditames dessa base curricular, que, como sabemos, teve uma tramitação sensivelmente polemizada pelos educadores nas diversas entidades, uma vez que sua aprovação acontecia para atender a um modelo de currículo padrão para todo o País, elaborado de acordo com uma visão tecnicista/instrumental, favorável às orientações dos grupos empresariais, interessados em formar um trabalhador que lhes fosse submisso, a partir, portanto, de um currículo próximo do que poderíamos chamar de mínimo e muito distante de uma base curricular que lhe propiciasse formação capaz de desenvolver sua autonomia e criticidade.

\section{Do teor da Resolução CNE/CP no 02/2015}

Relendo, hoje, os doze "considerandos" que embasam teórica e politicamente a Resolução CNE/CP nº 2/2015, tem-se a clara percepção de que ali estão sintetizados os fundamentos da educação brasileira construídos ao longo de pelo menos três décadas pelos educadores progressistas. Veja-se, por exemplo, a densidade do excerto abaixo transcrito:

CONSIDERANDO que a igualdade de condições para o acesso e a permanência na escola; a liberdade de aprender, ensinar, pesquisar e divulgar a cultura, o pensamento, a arte e o saber; o pluralismo de ideias e de concepções pedagógicas; o respeito à liberdade e o apreço à tolerância; a valorização do profissional da educação; a gestão democrática do ensino público; a garantia de um padrão de qualidade; a valorização da experiência extraescolar; a vinculação entre a educação escolar, o trabalho e as práticas sociais; o respeito e a valorização da diversidade étnico-racial, entre outros, constituem princípios vitais para a melhoria e democratização da gestão e do ensino (BRASIL, 2015). 
Em seu conjunto, os "considerandos" desta resolução, que a contextualizam historicamente e lhe dão fundamentos, especialmente neste item específico, traduzem uma compreensão de Estado e de sociedade capazes de abrigar uma determinada concepção de educação. Estão colocados nessa abertura e ao longo de todo o documento os princípios fundantes da educação brasileira, entre os quais, escolhemos como exemplar e por sua hoje quase profética importância, o seguinte:

(...) a educação em e para os Direitos Humanos é um direito fundamental, constituindo uma parte do direito à educação e, também, uma mediação para efetivar o conjunto dos Direitos Humanos reconhecidos pelo Estado Brasileiro em seu ordenamento jurídico e pelos países que lutam pelo fortalecimento da democracia, uma vez que a Educação em Direitos Humanos é uma necessidade estratégica na formação dos profissionais do magistério e na ação educativa em consonância com as Diretrizes Nacionais para a Educação em Direitos Humanos (BRASIL, 2015).

Na Resolução CNE/CP nº 02/2015, em seu Capítulo I, no qual trata Das Disposições Gerais, são definidos os princípios, os fundamentos, a dinâmica formativa e os procedimentos a serem observados nas políticas, na gestão e nos programas e cursos de formação de professores para a educação básica, além de regulamentar o planejamento, os processos de avaliação e de regulação das instituições formadoras. É também nesse capítulo que se reforça a necessária e orgânica relação entre a formação inicial e a formação continuada dos profissionais do magistério, nos termos do Artigo 62 da LDB, responsabilidade dos sistemas de ensino, que as promoverão em estreita articulação com as instituições formadoras. É ainda aqui que se colocam os condicionantes das políticas de formação e de como as instituições de ensino superior devem se organizar para atender essa demanda, sempre considerando os padrões de qualidade exigidos pelas políticas de formação e pelo que preconizam as Diretrizes Curriculares Nacionais para a Formação Inicial e Continuada em Nível Superior de Profissionais do Magistério para a Educação Básica, Resolução CNE/CP no 02/2015.

No capítulo I, por fim, define-se o que seja a docência, o que a compõe e quais são suas dimensões. Estabelecem-se, ainda, na sequência desses artigos, as definições de formação inicial e de formação continuada, descrevendo também as etapas e as modalidades de ensino que constituem a educação básica, além de deixar claro o que se entende por educação e o contexto em que se realiza. Explicita, em seguida, quem são, o que fazem e como se formam os profissionais da educação, evidenciando os princípios de sua formação. Finalmente, nos artigos que encerram esse capítulo, trata das instituições formadoras e do regime de colaboração que deve organizar a relação entre elas e o aparelho de Estado. Todos esses temas, que apenas foram aqui rapidamente mencionados, são tratados de forma exaustiva e muito bem organizada no primeiro capítulo.

No Capítulo II, o tema é a Formação dos Profissionais do Magistério para a Educação Básica no que caracteriza essa resolução como uma base comum nacional para os 
cursos de formação de professores. Vale aqui realçar a importância do item VIII acerca das expectativas de onde o egresso pudesse chegar em seu processo de formação: “à consolidação da educação inclusiva, através do respeito às diferenças, reconhecendo e valorizando a diversidade étnico-racial, de gênero, sexual, religiosa, de faixa geracional, entre outras". Nada mais importante, se consideradas as condições hoje presentes em nossa perturbada condição de convívio social.

O Capítulo III faz indicações sobre os conhecimentos a serem valorizados e que são fundamentais para compreender a instituição educativa onde o futuro professor irá atuar; a possibilidade de pesquisar e de aplicar os resultados de suas investigações; colaborar para que sua boa atuação profissional no ensino, na gestão dos processos educativos e na organização e gestão de instituições educativas no nível da educação básica. Neste capítulo encontram-se descritas as principais atividades que um professor poderá ser chamado a desenvolver em seu cotidiano de trabalho.

Os Capítulos IV e V são centrais na Resolução e tratam da Formação Inicial do Magistério da Educação Básica em Nível Superior, de sua estrutura e de seu currículo, podendo ser considerados os mais prescritivos da Resolução CNE/CP 02/2015. Neles estão descritos os conteúdos e a organização dos cursos de formação desses profissionais. São sete artigos que descrevem como formar os professores da educação básica.

O Capítulo VI introduz o tema da Formação Continuada dos Profissionais do Magistério, anteriormente tratado em legislações temporárias e desenvolvidas em eventuais programas de formação em serviço. Dedica-se, pois, a um tema que passou a figurar como necessidade imperiosa nos tempos atuais. Diz a que veio no Artigo 16, qual seja:

A formação continuada compreende dimensões coletivas, organizacionais e profissionais, bem como o repensar do processo pedagógico, dos saberes e valores, $\mathrm{e}$ envolve atividades de extensão, grupos de estudos, reuniões pedagógicas, cursos, programas e ações para além da formação mínima exigida ao exercício do magistério na educação básica, tendo como principal finalidade a reflexão sobre a prática educacional e a busca de aperfeiçoamento técnico-pedagógico, ético e político do profissional docente (BRASIL, 2015, Art.16).

O Capítulo VII, que trata da política de valorização dos profissionais do magistério da Educação Básica, deve ser saudado como a grande novidade numa legislação dessa natureza. Sua inserção expressa uma conquista histórica dos educadores organizados em suas entidades representativas, bem como de suas lutas sindicais por salários condignos.

Finalmente, o Capítulo VIII trata das disposições transitórias, no qual se define basicamente o prazo em que as instituições formativas deveriam se adaptar aos ditames da nova resolução, ao mesmo tempo em que organiza o funcionamento do sistema em relação aos pedidos de autorização para funcionamento de cursos de licenciatura e também dos processos de avaliação. 
Em síntese, o texto, em suas dezesseis densas páginas, é um convite à reflexão teórica, filosófica, política e ética sobre o que é a docência, o que a compõe, quais são suas dimensões, como se formam os professores, que papel cabe ao Estado nesse processo, que princípios norteiam a base comum nacional para uma sólida formação para o magistério da educação básica, entre outras questões que cercam a temática. Nada foi esquecido. Tudo o que um dia os educadores organizados em suas entidades representativas pensaram e defenderam sobre esse assunto, de alguma forma, foi contemplado. Também não faltou, e como se fora um coroamento das considerações, a defesa forte e urgente dos profissionais da escola, deixando clara a importância de suas reivindicações por melhores condições de trabalho e de remuneração: "considerando a importância do profissional do magistério e de sua valorização profissional, assegurada pela garantia de formação inicial e continuada, plano de carreira, salário e condições dignas de trabalho" (BRASIL, 2015).

\section{Da longa trajetória da Resolução 02/2015 à apressada votação das novas DCNFP}

Houve forte aceitação do conteúdo da Resolução CNE/CP nํ 02/2015 entre os educadores. Surgiram, entretanto, questionamentos ao Artigo 22, que se referia ao prazo para sua implantação e cujo adiamento materializou-se na Resolução CNE/CP no 1, de 9 de

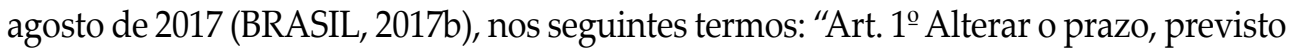
no Art. 22, da Resolução CNE/CP nํㅡㄹ 2 de $1^{\circ}$ de julho de 2015, que passa a ter a seguinte redação: Art. 22. Os cursos de formação de professores, que se encontram em funcionamento, deverão se adaptar a esta Resolução no prazo de 3 (três) anos, a contar da data de sua publicação".

Na disputa que se instalou entre aqueles que defendiam a imediata implantação da Resolução CNE/CP nº 02/2015 e os que advogavam por mais uma ampliação de prazo, para que a resolução incorporasse em sua redação a recém aprovada BNCC, foi exemplar a posição da Associação Nacional pela Formação dos Profissionais da Educação (Anfope), que assim se pronunciou em reunião convocada pela Comissão Bicameral do Conselho Nacional de Educação, em abril de 2018:

\footnotetext{
A Resolução CNE nº2/2015, que aprova as Diretrizes Curriculares Nacionais para a Formação de Professores, representa um consenso educacional sobre uma concepção formativa da docência que articula, indissociavelmente, a teoria e a prática, dentro de uma visão sócio histórica e emancipadora, defendida pelas entidades acadêmicas do campo da educação, e fruto de ampla discussão com a sociedade, tanto no âmbito das instituições universitárias quanto em Audiências públicas, promovidas inclusive pelo $\mathrm{CNE}$, e amplificada em inúmeros eventos acadêmicos e publicações do campo educacional. Defendemos que os projetos institucionais de formação sejam construídos ancorados nesta resolução, em fase de implantação nas IES de todo o país, por determinação do próprio CNE [...]. Defendemos as proposiç̧ões da Resolução 02/2015, que, ancoradas no PNE 2014-2024, fortalecem uma concepção
} 
de formação indissociável de uma política de valorização profissional dos professores para formação, carreira e condições de trabalho, com implementação do piso salarial em todos os estados e municípios; de promoção de concursos públicos para docentes da educação básica, impedindo a contratação de professores em caráter precário e sem a formação adequada (ANFOPE, 2018).

Mesmo com esses apoios, novos prazos para a implantação dessa resolução foram solicitados. O primeiro deles terminaria em julho de 2018, porém, em junho do mesmo ano, o então ministro da Educação solicitaria ao CNE outra prorrogação, sob o argumento de que seria importante que os currículos dos cursos de formação de professores se adequassem à nova BNCC, conforme redação da Lei no 13.415, de 16 de fevereiro de 2017 (BRASIL, 2017a), em seu Art. 7º que vincula os currículos dos cursos de formação de docentes à Base Nacional Comum Curricular. Nesse ínterim, a Associação Nacional dos Dirigentes das Instituições Federais de Ensino Superior (Andifes) também indicava a necessidade de ampliação do prazo de implantação da Resolução CNE/CP no 2/2015 até julho de 2019, alegando que várias IES estavam tendo dificuldades em reformular seus cursos de licenciatura dentro do período aprazado.

Cada vez mais, no entanto, ficava evidente a tentativa de setores governamentais, e inclusive da Andifes, em adiar a implantação da referida Resolução. Por outro lado, as entidades representativas dos educadores tais como a Associação pela Formação dos Profissionais da Educação (Anfope), a Associação Nacional de Pós-graduação e Pesquisa em Educação (Anped), a Associação Brasileira de Currículo (ABdC), a Associação Nacional de Política e Administração da Educação (Anpae) e a Confederação Nacional dos Trabalhadores da Educação (CNTE), entre outras, tinham clareza de que não se deveria aceitar novos adiamentos de prazo para sua implementação. Urgia que ela entrasse em vigor, anulando todas as disposições em contrário, antes que outra normativa mais consentânea ao momento político regressivo no país fosse aventada. Foi, então, forte e consequente a manifestação conjunta publicada pelas entidades de educadores, as quais deixavam explícita sua rejeição às reais intenções do CNE/MEC.

Enquanto aconteciam esses movimentos sistemáticos de adiamento/interrupção/ bloqueio da implantação da Resolução CNE/CP 02/2015, agora já claramente percebidos como parte da estratégia de retirá-la de cena, ação protagonizada pelo grupo pró governo instalado no $\mathrm{CNE}$, era urgente que esse mesmo grupo de conselheiros encontrasse rapidamente formas de modificar seu conteúdo ou mesmo de elaborar nova legislação que a substituísse. Começou, assim, uma corrida contra o tempo para trazer à pauta do CNE uma proposta que antagonizasse a Resolução CNE/CP 02/2015. Conforme o Conselheiro Mozart Neves Ramos (2019) em artigo publicado na Folha de São Paulo, edição do dia 24 de novembro último, o processo para a discussão da nova proposta teria sido iniciado com o encaminhamento feito pelo então ministro da Educação - Rossieli Soares ao CNE, em dezembro de 2018, de um documento denominado Proposta para Base Nacional 
Comum da Formação de Professores da Educação Básica. O texto apresentava as competências profissionais docentes, com base em três dimensões: conhecimento profissional, prática profissional e engajamento profissional. Antecedido de dez competências gerais docentes, as três dimensões, denominadas de competências específicas vinham acompanhadas das correspondentes habilidades. Tal documento encontra-se agora anexo às novas Diretrizes Curriculares Nacionais (DCN) para a Formação Inicial de Professores para a Educação Básica - da educação infantil ao ensino médio, sob a denominação de Base Nacional Comum para a Formação Inicial de Professores da Educação Básica (BNC-Formação). As novas diretrizes, segundo o conselheiro Ramos, no artigo citado, teriam sido formuladas tomando como referência a Resolução nº 2/2015, do CNE, "um belo trabalho, que precisava ser revisto e atualizado para dialogar com a BNCC".

Ao longo do ano de 2019, após algumas audiências públicas com diferentes atores da comunidade educacional, as novas diretrizes foram sendo elaboradas. Cabe considerar, contudo, que tais discussões, pouco ou nada serviram para demover o objetivo central da elaboração precoce de uma nova legislação para a formação dos docentes da educação básica: atender ao denominado "diálogo" com a BNCC da Educação Básica. Essa normatização curricular, segundo Aguiar e Dourado (2019, p.35), foi formulada nas gestões de quatro ministros de educação, com ritos, concepções e dinâmicas variadas, mas que passou a ser o carro-chefe das políticas desenvolvidas pelo MEC, tornando-se, mesmo, "ponto nodal para uma ampla reforma da educação básica, o que abrangia a formalização e a articulação entre currículos escolares, a formação de professores, a gestão da educação e os processos avaliativos" sendo que a "formação dos professores sobressai especialmente, por ser estratégica para concretizar a reforma da educação básica em curso, atendendo aos reclamos do mercado, que pugna pela formação do sujeito produtivo e disciplinado" (AGUIAR E DOURADO, 2019, p.35).

Restava evidente que a correlação de forças no CNE pendia agora para os conservadores, inclusive com o apoio já não mais envergonhado de antigos subscritores da Resolução CNE/CP nº 02/2015. Assim, ainda conforme Ramos (2019), o Conselho Nacional de Educação, em reunião de seu Conselho Pleno de novembro, aprovou por unanimidade as Diretrizes Curriculares Nacionais (DCN) para a Formação Inicial de Professores para a Educação Básica - da educação infantil ao ensino médio e a Base Nacional Comum-BNC-Formação (BRASIL, 2019b).

\section{DCN para a Formação Inicial de professores: da educação infantil ao ensino médio}

Com a justificativa de que a Resolução CNE/CP nº 02/2015 precisaria ser reformulada para incorporar como referência norteadora para os cursos de formação de professores 
a BNCC, aprovada em dezembro de 2017 (BRASIL, 2017b) para o Ensino Fundamental e em 2018 para o Ensino Médio (BRASIL, 2018), instalou-se no CNE a discussão dessas reformulações, processo que acabou se transformando na elaboração de um novo parecer e de sua consequente resolução sobre as Diretrizes Curriculares Nacionais e Base Comum para a Formação Inicial e Continuada de Professores da Educação Básica. O documento que sustentava essa investida estava agora em terceira versão e fora apresentado para consulta pública no mês de setembro de 2019. Até 23 de outubro, data posteriormente prorrogada para 30 de outubro de 2019, o CNE receberia contribuições ao parecer. Cogitava-se, a partir de então, que a qualquer momento ele poderia ser colocado em pauta, tornando-se objeto de discussão e votação em plenário.

Este cenário de risco iminente mobilizou fortemente as entidades representativas dos educadores que, prontamente, reagiram com várias manifestações em contrário a esta intempestiva e indesejada iniciativa. Assim, em nove de outubro, um dia após a Audiência Pública realizada pelo CNE sobre o tema, era divulgada a "Nota das entidades nacionais em defesa da Resolução 02/2015", que, em letras garrafais, assim identificava sua posição: Contra a Descaracterização da Formação de Professores (ANFOPE et. al., 2019). Este manifesto, de cujo teor transcrevemos abaixo alguns extratos, representa inúmeros coletivos. Sua abrangência, portanto, não deixa dúvidas sobre sua importância e poder mobilizador. Senão, vejamos:

[...] A versão três da Proposta de Reformulação da Resolução, apenas agora disponibilizada pelo $\mathrm{CNE}$, apresenta proposições que destroem as políticas já instituídas; desconsideram a produção e o pensamento educacional brasileiro ao retomarem concepções ultrapassadas como a pedagogia das competências; apresentam uma visão restrita e instrumental de docência e negativa dos professores; descaracterizam os núcleos formativos, a formação pedagógica e a segunda licenciatura; ignoram a diversidade nacional, a autonomia pedagógica das instituições formadoras e sua relação com a educação básica; relativizam a importância dos estágios supervisionados, retrocedendo, desse modo, nos avanços que a área alcançou com a Resolução CNE/CP 02/2015. Repudiamos, também, a proposta de institucionalização de Institutos Superiores de Educação, assim como a proposição de referenciais docentes de caráter meritocrático para a valorização do professor [...] Reafirmamos nossa posição em defesa da Resolução CNE/CP 02/2015, pois esta fortalece uma concepção de formação indissociável de uma política de valorização profissional dos professores para formação, carreira e condições de trabalho e representa um consenso educacional sobre uma concepção formativa da docência que articula indissociavelmente a teoria e a prática, dentro de uma visão socio-histórica, emancipadora e inclusiva, defendida pelas entidades acadêmicas do campo da educação. Assim, nos manifestamos pela manutenção sem alterações e pela imediata implementação da Resolução 02/2015 (ANFOPE et. al., 2019, grifo nosso).

Destacamos nesta citação, particularmente, aspectos presentes nas novas diretrizes que contrariam a concepção educacional defendida pelas entidades representativas dos educadores. Mesmo correndo contra o tempo, além de manifestações coletivas como esta, várias entidades do campo educacional e acadêmico encaminharam individualmente ao 
CNE suas contribuições, entre elas a Anfope, que, no dia 23 de outubro, de 2019, solicitou as seguintes providências:

1) Arquivamento dos pareceres referente à proposta de revisão e atualização das "Diretrizes Nacionais e Base Nacional Comum Curricular para a Formação Inicial e Continuada de Professores da Educação Básica" em discussão no CNE; 2) Imediata implementação da Resolução CNE/CP n. 2/2015, sem alterações, e acompanhamento de sua materialização junto às IES. (ANFOPE, 2019a)

As justificativas para tais solicitações foram explicitadas na sequência do texto e diziam que:

A diretoria da ANFOPE considerou que não cabe nenhuma alteração das Diretrizes Curriculares Nacionais para a formação inicial em nível superior (cursos de licenciatura, cursos de formação pedagógica para graduados e cursos de segunda licenciatura) e para a formação continuada (Resolução 2/2015) em vigor, tendo em vista que as IES de todo o país estão em processo de sua implementação, dentro dos prazos estabelecidos pelo Conselho Nacional de Educação (CNE), e, ainda não houve qualquer avaliação de sua implementação. A proposta apresentada no parecer 3 descaracteriza a formação docente afrontando a concepção que defendemos historicamente, a saber, a Base Comum Nacional dos cursos de formação de professores, que articula indissociavelmente a formação e a valorização dos profissionais da educação, e portanto, não faremos nenhuma consideração pontual ao parecer como sugerido, pois nos opomos a ele na íntegra (ANFOPE, 2019a).

Apesar da pronta reação da comunidade educacional contra a proposta apresentada pelo CNE em 2019, de proscrever a Resolução CNE/CP nº 02/2015, a rapidez com que esse processo se desenvolveu, no entanto, superou todas as expectativas e, numa quinta-feira, no dia 07 de novembro de 2019, o parecer do relator Mozart Neves Ramos e a resolução sobre as Diretrizes Curriculares Nacionais e Base Nacional Comum para a Formação Inicial foram aprovados por unanimidade no Conselho Pleno do CNE, que, naquela infausta sessão, contou inclusive com a presença "inesperada" de secretários do MEC.

As reações da comunidade educacional não se fizeram esperar. Muitas manifestações individuais e coletivas foram publicadas nos dias que se seguiram à sessão do CNE, de 7 de novembro. As próprias universidades, por meio de suas instâncias e fórum de deliberações, manifestaram-se rapidamente a respeito, como atesta o documento do Colégio de Pró-Reitores de Graduação (Cograd), que reivindica a manutenção da Resolução CNE/CP nº 02/2015, a qual, segundo a referida entidade, ainda se encontrava em processo de implementação em grande parte das universidades federais. Afirma o texto, entre outras questões que:

A nota do COGRAD soma-se, portanto, à manifestação incisiva das 30 entidades da área contra a descaracterização da política de formação de professores, com a aprovação das novas DCNs e da Base Nacional Comum da Formação pelo CNE, no último dia 07 de novembro, em uma sessão/audiência pública totalmente esvaziada, desconhecendo o posicionamento das entidades. [...] a Resolução de 2015 
consolida princípios e concepções amadurecidos na reflexão promovida por entidades do campo educacional como Anfope, Anpae, Anped, Cedes e Forumdir, concepções estas que foram incorporadas em várias IES, aos Projetos Pedagógicos de Cursos (PPC's) de licenciaturas, e outras estão em adiantado processo de revisão, na perspectiva de atendimento às diretrizes emanadas pela Resolução 02/2015 (COGRAD, 2019).

A Anfope, entre outras entidades congêneres, também se manifestou imediatamente em nota pública nos seguintes termos:

Em tempo recorde, o CNE desprezando o posicionamento das entidades e seus argumentos, aprova em sessão pública, totalmente esvaziada, pois não divulgada, a 'nova' Resolução sem discussão com o campo educacional. Essa 'nova' Resolução é mais um retrocesso educacional pois descaracteriza a formação docente afrontando a concepção da Base Comum Nacional dos cursos de formação de professores, que articula indissociavelmente a formação e a valorização dos profissionais da educação, defendida historicamente pela ANFOPE. Essa aprovação acelerada, sem discussão, visa desmontar um processo em curso nas IES de todo o país, que nos últimos anos se dedicaram a reformular seus cursos de licenciatura conforme determinava a Resolução 02/2015, dentro do prazo previsto pelo CNE, que prorrogou sua implementação até dezembro de 2019. [...]. Tal medida compromete a elevação da qualidade dos cursos de formação e da educação brasileira, e anula os avanços propostos pela Resolução 02/2015 (ANFOPE, 2019b).

Todo o processo, que culminou com a aprovação intempestiva e apressada das DCN para a Formação Inicial de Professores para a Educação Básica - da Educação Infantil ao Ensino Médio, no CNE/MEC, precisa ser entendido a partir da compreensão das políticas educacionais de países como o nosso que defendem a manutenção das premissas neoliberais, as quais apostam, ainda, em um capitalismo que cada vez mais revela sua impossibilidade de ordenar uma nação com padrões de igualdade social e de justiça. Assim, confiam na privatização como a grande estratégia para solucionar o problema da equidade social, ao mesmo tempo em que, contraditoriamente, os fatos mundiais revelam, cada vez mais, a riqueza de poucos em confronto com a pobreza da grande maioria da população. Dessa forma, as decisões tomadas em relação à formação de docentes no país revelam uma estratégia que busca entregar à sociedade professores capazes de fornecer às empresas e ao sistema econômico indivíduos educados não para resistir à cassação dos seus direitos, mas sim para atender a uma ordem que preserve o sistema e suas desigualdades. Confirma esta leitura o estudo realizado por Evangelista, Fiera e Titton (2019), denominado Diretrizes para formação docente é aprovada na calada do dia: mais mercado, no qual se destaca o fato de que os conselheiros que elaboraram a resolução das diretrizes para a formação de professores, que acabou finalmente aprovada em sua versão 3, e aqueles que a aprovaram por unanimidade possuem relações ou vínculos explícitos com instituições do espectro da educação privada, com sua lógica empresarial voltada à ordenação do status quo. Entre elas, instituições privadas de ensino superior; empresas educacionais de capital aberto; Sistema S; movimentos empresariais; Organizações Sociais (OS), entre outros. Ainda segundo o estudo mencionado, 
apenas dois conselheiros da Comissão Bicameral do CNE teriam vínculos com instituições públicas de ensino superior. ${ }^{1}$

Cada vez mais o professor deverá ter sua formação intrinsecamente ordenada pela BNCC, formulada no interior de uma política de reorientação curricular adotada por vários países, entre eles o Brasil, cujas alianças sociais, políticas e econômicas estão sendo construídas no interior da racionalidade neoliberal na educação, que atende prioritariamente aos interesses dos setores privados em sua lógica empresarial (DARDOT; LAVAL, 2016; HYPOLITO, 2019). Em concordância com esta análise, a padronização dos currículos e sua relação com exames nacionais, numa concepção de que boa escola é aquela que obtém bons resultados nas avaliações, em geral, censitárias (FREITAS, 2019).

\section{À guisa de epílogo...}

A luta apenas começou. E continuará. As entidades de educadores não esmorecerão no combate ao retrocesso contido na recém aprovada resolução pelo $\mathrm{CNE}$, que foi recentemente homologada, em 19 de dezembro último, por meio da Portaria no 2.167 (BRASIL, 2019c), assinada pelo ministro [substituto] da Educação, Antônio Paulo Vogel de Medeiros, que define as novas Diretrizes Curriculares para Formação Inicial de Professores da Educação Básica e Institui a Base Nacional Comum para a Formação Inicial de Professores da Educação Básica (BNC-Formação). Precisamos combatê-la publicamente, como vimos fazendo, deixando claro que seus pressupostos descaracterizam a formação docente cuja concepção nossas entidades representativas defendem historicamente. Os fundamentos desta legislação partem de princípios que são incompatíveis com aqueles que sustentam as Diretrizes Curriculares Nacionais para a Formação Inicial e Continuada em Nível Superior de Profissionais do Magistério para a Educação Básica, conforme a Resolução CNE/CP no 02/2015, principalmente no que diz respeito à articulação orgânica que esta faz entre formação e valorização dos profissionais da educação, enfatizando de forma inaugural a importância da formação continuada desses profissionais. Este último aspecto, inclusive, postergado pela nova legislação.

Recebido em: 20/11/2019 e Aprovado em 10/12/2019

\section{Notas}

1 A versão aprovada das DCN para a formação em 2019 pela Comissão Bicameral designada pelo CNE teve Maria Helena Guimarães Castro, da Câmara da Educação Básica (CEB), como coordenadora ou presiden- 
te; contou com a relatoria de Mozart Neves Ramos, também da CEB e representante do Instituto Ayrton Senna. Os outros conselheiros são: pela CEB, Alessio Costa Lima, Aurina Oliveira Santana, Ivan Cláudio Pereira Siqueira, Nilma Santos Fontanive e Suely Melo de Castro Menezes; pela Câmara da Educação Superior (CES), Antonio Carbonari Netto, Luiz Roberto Liza Curi e Marília Ancona Lopez (Evangelista; Fiera \& Titton, 2019).

\section{Referências}

AGUIAR, Márcia Angela da S; DOURADO, Luiz Fernandes. BNCC e formação de professores: concepções, tensões, atores e estratégias. Retratos da Escola, Brasília, CNTE, v.13, n. 25, p. 33-37, jan./mai. de 2019.

ANFOPE. Reunião da Comissão Bicameral do Conselho Nacional de Educação sobre a Formação Inicial e Continuada de Professores. Brasília, 2018. Disponível em: https://www.anfope.org.br/wpcontent/uploads/2018/05/ANFOPE-CNE-9abr-2018-.pdf. Acessado em: 03/12/2019.

ANFOPE. A ANFOPE se posiciona em defesa da Resolução 02/215 e pede arquivamento do parecer que propõe a sua alteração, [página online], 2019a. Disponível em: http://www.anfope.org.br/anfope-seposiciona-em-defesa-da-resolucao-02-215-e-pede-arquivamento-do-parecer-que-propoe-a-sua-alteracao/. Acessado em: 03/12/2019.

ANFOPE. A Anfope repudia a aprovação pelo CNE da Resolução que define as novas Diretrizes Curriculares para Formação Inicial de Professores da Educação Básica e Institui a Base Nacional Comum para a Formação Inicial de Professores da Educação Básica (BNC-Formação), em sessão realizada no dia 07 de novembro, sem divulgação. Em um plenário esvaziado. [página online], 2019b. Disponível em: http://www.anfope.org.br/anfope-repudia-a-aprovacao-pelo-cne-da-resolucao-quedefine-as-novas-diretrizes-curriculares-para-formacao-inicial-de-professores-da-educacao-basica-einstitui-a-base-nacional-comum-para-a-formacao-in/. Acessado em 03/12/2019.

ANFOPE; et al. Contra a descaracterização da Formação de Professores. Nota das entidades nacionais em defesa da Re. solução 02 /2015. [página online], 2019. Acessado em: 03/12/2019.

BRASIL. Lei no 9.394/96, de 20 de dezembro de 1996. Estabelece as Diretrizes e Bases da Educação Nacional. Brasília, 1996.

BRASIL. Resolução CNE/CP nº 1, de 18 de fevereiro de 2002. Institui Diretrizes Curriculares Nacionais para a Formação de Professores da Educação Básica, em nível superior, curso de licenciatura, de graduação plena. Brasília, 2002a.

BRASIL. Resolução CNE/CP no 2, de 19 de fevereiro de 2002. Institui a duração e a carga horária dos cursos de licenciatura, de graduação plena, de formação de professores da Educação Básica em nível superior. Brasília, 2002b.

BRASIL. Resolução CNE/CP nํㅜ 2, de $\mathbf{1}^{0}$ de julho de 2015. Define as Diretrizes Curriculares Nacionais para a formação inicial em nível superior (cursos de licenciatura, cursos de formação pedagógica para graduados e cursos de segunda licenciatura) e para a formação continuada. Brasília, 2015.

BRASIL. Lei $\mathbf{n}^{\mathbf{0}} \mathbf{1 3 . 4 1 5}$, de 16 de fevereiro de 2017. Altera as Leis no 9.394, de 20 de dezembro de 1996, que estabelece as diretrizes e bases da educação nacional, e 11.494, de 20 de junho 2007, que regulamenta o Fundo de Manutenção e Desenvolvimento da Educação Básica e de Valorização dos Profissionais da Educação, a Consolidação das Leis do Trabalho - CLT, aprovada pelo Decreto-Lei no 5.452 , de $1^{\circ}$ de maio de 1943, e o Decreto-Lei no 236, de 28 de fevereiro de 1967; revoga a Lei no 11.161, de 5 de agosto de 
2005; e institui a Política de Fomento à Implementação de Escolas de Ensino Médio em Tempo Integral. Brasília, 2017a.

BRASIL. Resolução CNE/CP no 1, de 9 de agosto de 2017. Altera o Art. 22 da Resolução CNE/CP noํㄹ, de $1^{\circ}$ de 2015, que define as Diretrizes Curriculares Nacionais para a formação inicial em nível superior (cursos de licenciatura, cursos de formação pedagógica para graduados e cursos de segunda licenciatura) e para a formação continuada. Brasília, 2017b.

BRASIL. Resolução CNE/CP nº 3, de 3 de outubro de 2018. Altera o Art. 22 da Resolução CNE/CP nํ2, de $1^{\underline{0}}$ de 2015, que define as Diretrizes Curriculares Nacionais para a formação inicial em nível superior (cursos de licenciatura, cursos de formação pedagógica para graduados e cursos de segunda licenciatura) e para a formação continuada. Brasília, 2018.

BRASIL. Resolução CNE/CP no 1, de 2 de julho de 2019. Altera o Art. 22 da Resolução CNE/CP noํㄹ, de $1^{\circ}$ de julho de 2015, que define as Diretrizes Curriculares Nacionais para a formação inicial em nível superior (cursos de licenciatura, cursos de formação pedagógica para graduados e cursos de segunda licenciatura) e para a formação continuada. Brasília, 2019a.

BRASIL. Resolução CNE/CP $n$ ํㅜㄹ, de 20 de dezembro de 2019. Define as Diretrizes Curriculares Nacionais para a Formação Inicial de Professores para a Educação Básica e institui a Base Nacional Comum para a Formação Inicial de Professores da Educação Básica (BNC-Formação). Brasília, 2019b.

BRASIL. Portaria no 2.167, de 19 de dezembro de 2019. Homologa o Parecer CNE/CP no 22/2019, do Conselho Pleno do Conselho Nacional de Educação, que, junto ao Projeto de Resolução a ele anexo, define as Diretrizes Curriculares Nacionais para a Formação Inicial de Professores para a Educação Básica e institui a Base Nacional Comum para a Formação Inicial de Professores da Educação Básica BNC Formação. Brasília, 2019c.

COGRAD. Manifestação - diretrizes curriculares nacionais para a formação de professores. 2019. Disponível em: http://apub.org.br/wp-content/uploads/2019/11/Manifestac\%CC\%A7a\%CC\%83oCOGRAD-DCNs-formac\%CC\%A7a\%CC\%83o-de-professores.pdf. Acessado em: 03/12/2019.

DARDOT, P.; LAVAL, C. A nova razão do mundo: ensaio sobre a sociedade neoliberal. São Paulo: Editora Boitempo, 2016.

EVANGELISTA, Olinda; FIERA, Letícia \& TITTON, Mauro. [Debate] Diretrizes para formação docente é aprovada na calada do dia: mais mercado. Universidade à esquerda: jornal independente e socialista. Online. Publicado 14/11/2019.

FREITAS, Helena Costa Lopes de. CNE ignora entidades da área e aprova Parecer e Resolução sobre BNC da Formação (atualizado). Formação de professores - blog da Helena. Publicado em 07/11/2019.

HYPOLITO, Álvaro M. BNCC, agenda global e formação docente. Retratos da Escola, Brasília, CNTE, v. 13, n. 25, jan./mai. 2019.

RAMOS, Mozart Neves. Novas diretrizes para a formação de professores. Qualidade do docente é o fator principal na educação. Folha de São Paulo, edição de 24 de novembro. São Paulo, 2019. 